\title{
Towards a general model of quality assessment in higher education
}

\author{
FRANS A. VAN VUGHT \& DON F. WESTERHEIJDEN \\ Center for Higher Education Policy Studies, University of Twente, P.O. Box 217, 7500 AE Enschede, \\ The Netherlands
}

\begin{abstract}
In this article a number of elements of a general model of quality assessment in higher education are presented. On the one hand these elements are put in a historical context of quality assessment in Medieval universities and, on the other hand, deduced from the recent experiences with quality assessment in both North-American and Western European countries. With respect to the historical context a distinction is made between the intrinsic and the extrinsic values of higher education. Two types of quality assessment related to these values are also distinguished. Concerning the recent experiences with quality assessment systems, the practices in the U.S.A., Canada, France, the Netherlands and the United Kingdom are explored. In the final section the general mode of quality assessment is discussed in the context of the distinction between the intrinsic and the extrinsic values of higher education.
\end{abstract}

\section{The historical roots of quality assessment in higher education}

From the early days of higher education on, the assessment of the quality of its processes and products has been an important focus of attention for higher education institutions. In this historical attention for quality a certain tension is found which we nowadays still experience and which sometimes appears to be the source of heated debates.

Already in Medieval higher education a distinction can be made between two extreme models of quality assessment. Neither of these two models is of course found in the actual history of European higher education. The models rather point to two crucial dimensions of quality assessment in higher education. Referring to their historical backgrounds, we will call one model the French model of vesting control in an external authority (Cobban 1988, p. 124). The other model we will call the English model of a self-governing community of fellows.

The French model can be illustrated by the dramatic struggle for autonomy by the University of Paris in the early thirteenth century. It was the chancellor of the cathedral of Nôtre Dame, acting as the delegate of the bishop of Paris, who represented the then dominating episcopal outlook that the universities should be seen as 'ecclesiastical colonies.' The universities were viewed as higher forms of education that were, however, to be integrated in the ecclesiastical structure and that were to remain under episcopal authority. The chancellor of the cathedral of Nôtre Dame was an external official set above the masters' guild. As such he claimed the authority to grant or to withhold the teaching license and he claimed the right to decide about the content of studies. The masters fought the chancellor's authority. And after a long and bitter conflict, Pope Gregory IX in his bull called 
Parens Scientiarum (1231) finally made an end to the dominance of the bishop and the chancellor over the masters' guild (Cobban 1975, pp. 76-84).

The English model of self-governance has its origins in the aspirations of the masters at the Medieval Universities of Oxford and Cambridge to be completely independent of external jurisdiction. English Medieval colleges were sovereign, self-governing communities of fellows. In the English colleges the fellows themselves had the right to remove unsuitable masters and to co-opt new members. It was up to the community of the fellows to judge the quality of their colleagues.

The French model may be considered to be the archetype of quality assessment in terms of accountability. In the French model the power to decide what should be studied and who could be allowed to teach at the university was in the hands of an external authority. The guild masters were accountable to the chancellor for the contents of their teaching. The English model is the expression of what we nowadays call: quality assessment by means of peer review. The masters decided among themselves what should be taught and who should teach.

The French and the English models can, we think, be considered to be two important dimensions of any present-day system of quality assessment in higher education. Both the dimension of providing accountability (the French model) and the dimension of peer review (the English model) are crucial elements of presentday quality management systems in higher education.

These two dimensions refer to the two subcategories of the general concept of quality that have always played a central role in higher education. Looking at the history of higher education, it can be argued that higher education has always had both intrinsic and extrinsic qualities. The intrinsic qualities refer to the ideals of the search for truth and the pursuit of knowledge. The extrinsic qualities are related to the services higher education institutions provide to society. Already in the early days of higher education, these two categories of quality can be found. Higher education institutions have always espoused the values and ideals of the search for truth and the disinterested pursuit of knowledge. At the same time, through the centuries the institutions of higher education have been able to respond to the needs of society. Higher education institutions have adapted themselves with great flexibility to the changing needs and opportunities in their environment. By combining both intrinsic and extrinsic qualities, higher education institutions have been able to show a remarkable historical persistence. The combination of intrinsic and extrinsic qualities has helped higher education institutions to capture their important place in history and society.

\section{The recent call of higher education quality assessment}

Since the early 1980 s quality has become a central concept in many discussions on higher education. In the United States and Canada the debates on the various approaches and instruments with respect to quality assessment have intensified. In the United Kingdom (in 1984) quality was declared to be a principal objective for higher education. In France the 'Comité National d'Evaluation' was set up. In the 
Netherlands an influential policy-paper was published in which quality played a major role. In Denmark, Finland, Spain and several other countries the first steps were taken to design a quality assessment system (Neave and van Vught 1991, van Vught and Westerheijden 1993).

There are various factors that can explain this recent increase of the attention for quality in higher education. An important factor is the expansion of the various higher education systems. The rapid growth of the student-body and the accompanying increase of the number of fields of study, departments and even whole new institutions have triggered questions about the amount and direction of public expenditure for higher education. Another (related) factor lies in the simple fact that the limits of public expenditure have been reached in many countries. Budget-cuts and retrenchment operations automatically lead to questions about the relative quality of processes and products in higher education. A third factor concerns the transition process to technology-based economies, which in many countries brings along policies to guide student demand to fields that are perceived to be important for further economic development (Neave 1986, p. 168).

These factors indicate that during the last ten years or so, especially the extrinsic values of higher education have driven many governments to policies of quality control in higher education. The increasing costs of higher education systems had to be legitimised by clearly definable societal benefits. And for this, mechanisms and procedures of quality assessment were deemed to be necessary.

New systems of quality assessment and quality control have been (or are being) developed in several countries. But, while it may be clear that the extrinsic values of higher education are important factors stimulating these developments, it appears to be difficult to combine in the new systems of quality assessment on the one hand the government's goals regarding the national higher education system and on the other hand the views and characteristics of the higher education institutions.

In this article we will briefly discuss the experiences with quality assessment in a few relevant countries. From this discussion we will try to deduce a number of elements of a general model of higher education quality assessment, which may be applicable in various contexts. Finally, we will present a brief analysis of this general model, using the concepts of intrinsic and extrinsic qualities that were distinguished before.

\section{Experiences in the U.S.A. and Canada}

As is well known, in the United States and Canada, the market is the dominant form of coordination in higher education. Competition between higher education institutions is generally accepted. Higher education institutions are organised on a basis which to a considerable extent is similar to private corporations. There is considerable power at the top of the higher educational institution. And these institutions have a board and a president, rather like private corporations. Although the influence of governmental steering is not completely absent, compared to for 
instance, continental Europe this influence is limited. The higher education institutions in the United States and Canada are supposed to regulate themselves. If they do not, they will lose resources, students and scholars to their competitors.

In the United States the growing diversity in institutional forms and the initial lack of centrally defined standards led by the late nineteenth century to a level of chaos in the US higher education system. If the institutions would not have addressed this increasing level of chaos, strong government intervention would probably have become unavoidable. Because such an intervention was not attractive to the higher education institutions, the institutions took the initiative to develop themselves two processes of quality assessment (Kells 1989).

The first process of quality assessment is accreditation. Accreditation of a higher education institution or of a specific study programme within an institution consists of a procedure of self-assessment by the organisation seeking accreditation, followed by a visit of a team of external assessors and a final discussion, by a peerboard using pre-existing accreditation standards, on the question whether or not to give accreditation. In the U.S. accreditation has two forms. The first is institutional accreditation, conducted by regional bodies that are controlled by the higher education institutions themselves. The second form of accreditation is specialised accreditation conducted nationally by profession controlled bodies.

The second process of quality assessment in American higher education is the intra-institutional process of systematic review of study programmes. This review process is being used by universities: to assess programme quality, to enhance institutional decision-making, and in some cases to provide a basis for the redistribution of marginal resources within the institution (Barak 1982, Kells and van Vught 1988, Kells 1989). Program review may become an element of the broader accreditation process, but this is not necessarily the case.

In Canada, quality assessment in higher education is somewhat differently organised. In Canada quality assessment has not so much taken the form of a full process of accreditation. In this country two crucial elements of the U.S. type of accreditation have been chosen to be part of the dominant quality assessment approach: self-assessment and the visits by peers. For example, the technical schools and community colleges in British Columbia have employed such an approach, as has the provincial university of Alberta (Holdaway 1988).

So, in higher education systems with an emphasis on market coordination and a high level of institutional autonomy (at least compared to some continental European systems) we find an approach to quality assessment in which the following elements can be found:

a) a process of self-evaluation. In some cases the assessment is limited to this element. This is especially the case when the assessment takes the form of an intrainstitutional review process;

b) a review by peers, usually in the form of a visit by a team of external assessors;

c) finally, especially in the U.S., these two elements are brought together in a wider system of accreditation in which (except for self-evaluation and review by peers) 
one other element is crucial: the formulation of standards that are used to make the decision to give or withhold accreditation.

\section{Developments in Western Europe}

Contrary to the United States and Canada, the predominant form of coordination in the Western European higher education systems in many countries still is state control. With the exception of Britain, the Western European higher education systems have been heavily controlled by governments for a long period of time. In these centrally controlled continental Western European higher education systems the institutional autonomy was rather limited (and in many cases still is) and the funding was and is generally provided by the state.

During the 1970s and the 1980s the Western European higher education systems have been confronted with a number of far-reaching changes. Most of these changes can be related in one way or another to a shift in governmental strategies towards higher education. A major underlying political force was the rise to power of conservative governments in many of these countries. The so-called 'value-formoney' approach of these governments with respect to the public sector led to the end of the more or less unconditional government funding of public higher education. In practice this implied, among other things, that public funding of higher education was increasingly becoming linked to the performance of higher education institutions. As a consequence, the question of how to assess the performance, or quality, of higher education became one of the central issues in Western European higher education in the last decade.

A second important development in higher education policy-making in Western Europe is the rise of the governmental strategy of 'self-regulation' (van Vught 1989, Neave and van Vught 1991). During the second half of the 1980s, the ministries of education and higher education institutions especially in the countries of northwestern Europe have agreed upon the desirability of more self-regulation by the higher education institutions. In this period, several governments have advocated deregulation by central ministries and increased autonomy of and competitiveness among the higher education institutions.

The establishment of a governmental strategy directed towards more autonomy for higher education institutions was generally motivated by governments by the wish to stimulate the innovative behaviour of higher education institutions and especially to stimulate their responsiveness to the perceived needs of the economy and of society. Also, there was to be a greater awareness on the part of society and the public about the quality of study programmes, which implied that credible systems of quality assessment should be developed.

In some Western European countries new attempts to set up quality assessment systems arose from the developments described above. A quality assessment system was either initiated by the central governmental authorities (as was the case in France) or it was negotiated between governmental actors and the leaders of 
higher education institutions (as was the case in the Netherlands). Together with the United Kingdom, these two countries offer a good overview of the recent experiences with quality control in Western Europe. Let us briefly describe the developments in these three countries.

\section{France}

The President of the French Republic and an act of parliament brought into being the Comité National d'Evaluation (CNE) in 1985 as a result of the so-called Loi Savary. It was, accordingly, set up in a spirit of concern about the dysfunctions of the traditional, centralised, system of quality control: lack of actual autonomy, uniformity, rigidity, bureaucracy, etc. (Staropoli 1991, p. 45). Given its position in terms of constitutional law, the CNE is a government agency, but it only reports to the President, so it is independent of the Prime Minister, the Minister of Education and other executive agencies.

The CNE quality assessment procedure consists of two parts: institution-wide evaluations and 'horizontal,' disciplinary reviews. The evaluations are not specific down to the individual level, nor do they assess courses: these two levels are covered by traditional mechanisms. Where necessary and possible, the CNE makes use of existing evaluations and control reports of other agencies that do examine these and other aspects (e.g., CNRS Research laboratories). The tasks of the CNE are not only concerned with quality assessment, but also with judging, quite generally, the results of the contracts established between higher education institutions and the Ministry of Education. Many factual indicators are, therefore, at the basis of the CNE evaluations, including information as diverse as research and finance. Evaluation results are not used directly for making reallocations of funds, though through the contract negotiations and the annual budget negotiations, a firm link with decision-making is established.

The CNE makes institution-wide evaluations of education, research and management, the argument being that research and teaching are interdependent primary activities of higher education institutions. Also, other aspects of the higher education institution as an environment for teaching and research are examined. Evaluations are undertaken after an invitation by the higher education institution; it is a voluntary procedure, though the CNE has the right to undertake the evaluations it wants. The CNE 'tours' all institutions every eight years approximately. Each audit results in a report on the institution, making recommendations to the persons responsible for institutional management. These reports are public. They are sent, among others, to the ministers responsible for the higher education institutions visited, so as to assure the reports' roles in the negotiations mentioned above. The whole procedure, from invitation to report, takes about one year (see also Neave 1991).

The second part of the CNE procedure (the disciplinary reviews) consists, first, of self-evaluation reports provided by the institution to be visited. These reports are confidential (and include names of individuals). Second, the CNE, the institution 
involved and government offices collect statistical data. With those two sources and its own visit to the location, an external peer committee makes qualitative judgements, resulting in a public report. The committees work 'horizontally,' reviewing all courses in France in a broad disciplinary area.

Every year, the CNE presents a summary report to the President of the French Republic. In the reports the CNE gives an overview of its institution-wide evaluations. However, no explicit rankings are made of the institutions audited. The character of the reports is sometimes judged to be descriptive rather than analytical (Guin 1990).

\section{The Netherlands}

Following the publication of the policy paper entitled Higher Education: Autonomy and Quality (1985), the relationships between the Ministry of Education and Science and the higher education institutions in the Netherlands were restructured. In exchange for a greater degree of financial and managerial autonomy, the higher education institutions would prove to society that they delivered quality education. Originally, the government intended this evaluation to be executed by the, partly newly-established, Inspectorate for Higher Education (IHO). In subsequent discussions the umbrella organisations of the higher education institutions, the Association of Cooperating Universities in the Netherlands (VSNU) for the universities and the HBO Council for non-university higher education institutions, took that responsibility on themselves. The IHO was by-passed through that compromise and was largely left with the task of 'meta-evaluation': evaluation of the evaluation, and evaluation of the follow up on assessment results by the higher education institutions. A pilot project was held by the VSNU in 1988. As a consequence of the evaluation of the pilot project some adjustments were made and the quality assessment procedure became operational in 1989. In 1990 the HBO Council started a procedure in the non-university sector that, although not completely similar to the VSNU approach, is based on the same basic principles.

For reasons of brevity, we shall concentrate here on the VSNU system. The focal point of the VSNU quality assessment procedure is the visiting committee that reviews all study programmes in a given area of knowledge in the country; the approach is by disciplinary fields, rather than institutional. In a fixed six year cycle, in principle all study programmes are covered by the procedure.

In preparation for the visiting committee, each participating study programme is required to write a self-evaluation. As the aims of the self-evaluation are not only to prepare the faculty for the visiting committee, but also to stimulate internal quality management (Vroeijenstijn and Acherman 1990, p. 88), the content of the selfevaluation is not fixed completely: the faculties and departments to be evaluated can stress points which are important to them. However, for reasons of comparability, a fixed format is given by the VSNU checklist (VSNU 1990). The self-studies of all participating study programmes are collected by the visiting committee before it starts on its 'tour' of the country. 
The visiting committees consist of about seven members, including at least one foreign expert in the field. The members of the committee are proposed by the collective deans of the participating faculties and nominated by the boards of the VSNU. The committee visits each study programme for, normally, two or two and a half days. During this period the committee speaks with representatives of all interest groups in the faculty, including students. To enable non-selected voices to be heard, an 'open hour' is part of the procedure. Subjects for the talks are taken from the self-evaluation, from the committee's prior visits and other (usually considerable) knowledge of the field and the faculty, and whatever else comes up during the visit. At the end of the visit, the chair gives an oral, temporary judgement about the quality of the study programme. Based on the written version of this judgement and the (factual) comments of the study programmes, the visiting committee then writes its final report. The report usually contains a general part, stating problems, outlooks, expectations and recommendations pertaining to all of the field, and chapters about the individual study programmes.

As a rule, the recommendations in the visiting committee report lead to measures for improvement of the study programmes, together with measures taken based on the self-evaluations in anticipation of the visiting committee (IHO 1992, Frederiks et al. 1993).

As a result of the agreement of 1986, the Ministry of Education and Science has not taken any action on the basis of the visiting committees' judgements. It was thought that the introduction of the system should not be hampered by direct consequences for decision-making and funding. Direct links to funding and other aspects of government decision-making would lead only too easily to strategic behaviour on the part of the higher education institutions, which would undermine the quality assessment system completely.

\section{The United Kingdom}

In the United Kingdom, two models of quality management have been developed since the enlargement of government influence over higher education in the $1960 \mathrm{~s}$. The first model applies to the sector of non-university higher education, the polytechnics and colleges. Much later, quality assessment was extended to university higher education too. We shall characterise these models in their chronological order. After doing so, we will discuss the new arrangements with respect to quality assessment that are a result of the 1991 White Paper Higher Education: A New Framework, formalised in the Further and Higher Education Act of 1992.

Since the first half of the 1960 s non-university higher education in the UK was under the aegis of the Council of National Academic Awards (Brennan 1990). Like in other countries, quality in this higher education sector was also controlled by Her Majesty's Inspectorate (HMI), which continued to exist, with its own responsibilities and methods, alongside the new CNAA. The main characterising element of HMI procedures was classroom observation. 
The CNAA, a government-initiated body, was independent: it obtained its own royal charter in 1964. It was a degree-awarding body, giving out degrees of a professedly equal level to those of universities (bachelor's degree). The CNAA validated proposed courses in colleges and polytechnics ex ante and reviewed them quinquennially. For a long time the committees consisted of peers, i.e., academics working in the same area of knowledge but in other higher education institutions (colleges, polytechnics and universities), plus, if applicable, representatives of the relevant profession or industry. These committees based their visit on detailed written information regarding the structure and content of the course, ways and methods of teaching and student assessment, and available resources (research and teaching qualifications of the staff members who were expected to become involved, physical equipment, etc.). In the frequent cases of disapproval by the committee a new round, based on an amended proposal, would start.

The peer review of courses was complemented by a, usually quinquennial, review of the institution's own operational (i.e., not just existing on paper) mechanisms to assure the level of its courses. Later, since 1988, the CNAA accredited a number of polytechnics to validate their own courses (undergraduate and postgraduate degree level) through this procedure of monitoring the institutional quality management procedures.

Based on this tradition of government-independent quality assessment, the CNAA and the funding organisation of the public sector higher education institutions, the Polytechnics and Colleges Funding Council (PCFC), tried to liberalise the evaluation culture developing in the 1980 s, which was becoming more and more government-centred, by taking account of the institution's goals and aims.

When, in 1992, the binary system in the UK was abolished, the CNAA ceased to exist. Its activities ended with the academic year 1991-1992.

The turning points in quality management for British universities were two reports in the mid-1980s: the Reynolds report to the Universities' Grants Committee (UGC) and the Jarratt report to the Committee of Vice Chancellors and Principals (CVCP). In the Reynolds report criteria were laid down for internal quality management systems which all universities would be required to introduce in the following years. The Jarratt report was the focal point for the discussion of performance indicators and their role in quality-based funding.

The Academic Audit Unit (AAU) was introduced in 1990-1991 by the umbrella organisation of the universities, the Committee of Vice Chancellors and Principals (CVCP), reputedly to counter the threat of Her Majesty's Inspectorate (HMI) to extend its control to the universities (Young 1990). Before, each university individually took care of its own quality control. The external, comparative aspect in this system consisted of the external examiners. Views on the effectiveness of these external examiners in terms of quality assessment differ. However, this approach was judged to be an insufficient mechanism for providing accountability towards society in general and to the government in particular. The AAU had to fill this gap.

The AAU activities were a form of 'meta-evaluation': it did not evaluate the 
quality of higher education, but the quality of the institution's evaluation methods. The core of the AAU quality assessment procedure consisted on an on-site visit by an audit team. The teams consisted of academics, as a rule two or three persons. The choice of institutions to visit resulted from 'negotiated invitation.' In preparation for its (usually three day) visit the audit team received written information from the university on the quality assessment systems it had, plus - if requested - a small number of examples of the application of these systems. The AAU had a checklist based on good practice against which to assess an institution's quality assessment mechanisms. From this documentation together with the information gathered during the on-site visit the audit team drafted a short report for the university as a whole and, if necessary, confidential reports on 'sensitive issues' to the Vice-Chancellor. Following the institution's comments on this draft a final version was written of the official report. The AAU did not itself publish the report, but the university was encouraged to do so.

The changes following the 1991 White Paper have led to profound changes in the organisational structure of the intermediate level in the UK higher education system (between the individual institutions and the department of education); new procedures for these organisations have been drawn up.

Organisationally, the changes include primarily the following. First, the collective of heads of higher education institutions established the Higher Education Quality Council (HEQC) with a Division of Quality Audit, into which the AAU has been subsumed. The work of the CNAA in supporting and enhancing quality will also be developed for all of higher education by this Council. Second, the former funding councils (UFC and PCFC) have been transformed into three new funding councils, one for England, one for Wales and one for Scotland. These have set up Quality Assessment Committees to assist them in making funding decisions based on the quality of teaching in the separate institutions.

The White Paper also has led to the introduction of very specific meanings for the following terms in the British context:

- quality control: 'mechanisms within institutions for maintaining and enhancing the quality of their provisions';

- quality audit: "external scrutiny aimed at providing guarantees that institutions have suitable quality control mechanisms in place' (this is the responsibility of the HEQC);

- quality assessment: 'external review of, and judgements about, the quality of teaching and learning in institutions' (this is the responsibility of the funding councils).

In this way higher education institutions will be audited by one agency, and assessed by another. The quality audits by the HEQC resemble the basic principles of the AAU: an investigation of the quality control mechanisms and policies present in the individual institutions by a small team of external experts, including in loco audit trails to examine the practice of quality control.

Although on a more detailed level differences can be found between the 
approaches of the English and the Scottish funding councils (the Scottish funding council taking, e.g., a slightly more explicitly developmental and quality improvement oriented stance than the English one), on a general level they are fairly similar. Basically, the faculties are asked to provide information about themselves, in writing, on a limited number of indicators, and on their programme, resulting in a claim for 'excellent' or 'satisfactory' quality of teaching. The funding councils will compose small visiting committees from a pool of experts (primarily disciplinary peers), to assess and visit all institutions claiming excellence, all those where - based on information available to the funding council - weaknesses may be encountered, and to examine a sample of other institutions. Each visiting committee is selected to visit one institution; no effort is made to set up a nationwide system of comparisons. The committees' judgements are summarised as 'excellent,' 'satisfactory' or 'unsatisfactory." In what way, through which 'formula' (if any), the judgements will inform the funding decisions is not yet completely clear.

To what extent the practices of quality audit and quality assessment amount to the same thing in practice, cannot be told yet. Some fears exist that, e.g., an audit trail into the practice of quality control in a faculty will closely resemble the quality assessment of that same faculty.

\section{A general model of higher education quality assessment}

Overlooking the experiences with quality assessment systems both in the USA and Canada, and in the Western European countries just mentioned, it can be argued that in all these systems a number of similar elements are found that can be combined into the core of a general higher education quality assessment system. This general model thereby becomes an overall descriptive summary of the similar elements of several idiosyncratic systems. The various systems described before (as well as all other systems, not mentioned here) of course all have their own characteristics that apply to their own specific circumstances. But these systems also show some similar elements that can be combined into a general model.

What then could be common elements of a general model of higher education quality assessment?

A first element concerns the managing agent (or agents) of the quality assessment system. Such an agent should be independent and have the responsibility to manage the system at a meta-level. The meta-level agent should be the coordinator of the quality assessment system, acting independently from government politics and policies and not having the task to impose upon the institutions an approach that the government deems to be necessary. In the Western European context, the meta-level agent should preferably have some legal basis. In the higher education system of the USA, the accreditation agencies have the form of voluntary associations. But even in the USA there was some link to the legal structure through the recognition of accrediting agencies by the Council of 
Postsecondary Accreditation (COPA). Its coordinating task should imply (after consultation with the institutions) the formulation of procedures and formats that can be used by the institutions. In these procedures and formats consistent statistical information can be indicated as highly relevant. The experiences in the various countries in Western Europe show that exactly this meta-level role is of great importance to obtain acceptance of the system. The Academic Audit Unit (AAU) in the United Kingdom neither inspected courses nor programmes, nor did it validate courses. The AAU only monitored and commented on the mechanisms by which the institutions themselves assured the quality of the programmes they offer. Similarly, in the procedures used by the Council for National Academic Awards (CNAA) since 1985, the institutions were encouraged to undertake their own quality review processes. While the CNAA kept its responsibility for the final approval of the courses leading to its awards, the quality assessment mechanism first of all had to do with the institution's capacity to identify its strengths and weaknesses and to improve its quality. In the new British systems, two meta-level agents exist, namely the Higher Education Quality Council, 'owned' by the collective universities, and the funding councils, which are tied more closely to the governmental services. The Association of Co-operating Universities in the Netherlands (VSNU) follows a strategy similar to that of the CNAA and the CVCP. In the quality assessment system in the Netherlands emphasis is put on the institution's self-evaluation and the visit by peers. The Association itself only operates as the coordinator of the system.

A second common element may be deduced from both the North-American and the Western-European experiences. These experiences indicate that any quality assessment system must be based on self-evaluation (or: self-study, selfassessment). It is often argued in the higher education literature that, in order for academics to accept and implement changes, they must trust and 'own' the process in which problems are defined and solutions are designed. This is certainly also the case in quality assessment. Only if the academics accept quality assessment as their own activity, will the system be successful. Self-evaluation is a crucial mechanism for academics to accept a quality assessment system. Moreover, in a self-evaluation process (or in any set of activities in a higher education institution with a focus on internal quality assessment) consulting processes with outside actors (employers, alumni) is of great importance.

A third common element in a general model of quality assessment certainly appears to be the mechanism of peer review and especially one or more site visits by external experts. It is crucial that these external experts should be accepted by the institution to be visited as unbiased specialists in the field. They can come from many constituencies (including employers' organisations, industry and professional bodies) and, depending on the nature of the visit (review of content and level of a specific study programme, or management audit at the institutional level), they will need to have specific backgrounds (academic expertise, managerial experience, etc.). The external visitors should visit the institution (or faculty/department) for a period of a few days, during which they can discuss the self-evaluation report and the plans for future innovations with the faculty. The visitors could also take the 
opportunity to interview staff, students, administrators and (if possible) alumni. This element appears to be used successfully in both North-American and WesternEuropean quality assessment systems. In the USA and Canada a visit by peers always has been a crucial aspect of the various assessment systems. In the UK the CNAA emphasised the visit by a committee of peers. The Academic Audit Unit saw the visit as an intense and concentrated activity (Williams 1991, pp. 7, 8). The procedures developed since the changes in British higher education in 1992 continue this emphasis. Although for reasons of economy the funding councils abstain from visits to all faculties, all those whose quality is claimed or expected to deviate from the average will be visited, plus a sample of the 'satisfactory' ones. In France the Comité National d'Evaluation organises at least two visits to each university being reviewed. In the Netherlands a team of external experts visits each programme site of a specific discipline.

A fourth element of a general model of quality assessment concerns the reporting of the results of and experience with the methods used. Regarding this element it may first of all be pointed out that some form of reporting the conclusions of the peer review team is very useful. However, looking at the experiences, such a report should not have the function of judging or ranking the institutions or programmes that have been visited. It rather should have as its main objective to help the institutions and study programmes to improve their levels of quality. A crucial phase in the reporting process therefore concerns providing the opportunity to the institutions and units that have been visited to comment on a draft version of the report and to formulate counter-arguments, if necessary. Also, in the final version of the report higher education institutions should be able to indicate possible disagreements with the peer review team. Reporting the results of the quality assessment processes also is an important mechanism in the process of providing accountability to external constituencies. However, there appear to be various ways of offering such a report and each has its specific advantages and disadvantages. One way is to publish the complete report and, by so doing, offer it to all those who might be interested. The advantage of such an approach is that each constituency can immediately and clearly find out what the outcomes of an assessment have been and how these outcomes relate to their norms and criteria. A disadvantage of this approach is that it may severely limit the commitment of those who are visited to engage in open discussions with the peer review team, simply because they fear the effects of their frankness when the results of the review are published. A second way to report on the results of the peer review is to offer the detailed individual reports only to the institutions visited and to guarantee confidentiality. To the external constituencies (and to society at large) a general summary of the report can be presented, which may be used as a mechanism for providing accountability. The advantage of this approach is that the commitment of those who are visited will be high. The disadvantage is that some external constituencies might not be satisfied with only a summary of the report, out of fear that information is being withheld from them.

Regarding this element, the approaches in the various countries differ. In the USA and Canada the reports are usually kept confidential. In France, the CNE 
publishes its reports on the institutions. The institutional self-evaluations are kept confidential, while the report by the external experts is public. In the Netherlands, although in the pilot phase the reports on the individual study programmes of the external visitors were kept confidential, since the system has been fully implemented the final reports, including the 'local reports,' have been made public. The argument for doing so is the accountability objective. In the procedures of the British Academic Audit Unit the audit report was intended to provide an accurate account of an institution's quality assurance mechanisms. The report thereby drew attention to good and bad practice. The report was first of all written for the institution and the Academic Audit Unit itself did not publish the reports. It was for the institution to decide what publicity to give to its reports, although it was assumed that the report 'finds its way into the public domain accompanied by a commentary prepared by the university' (Williams 1991, p. 10).

A final common element of a general model of quality assessment concerns the possible relationship between the outcomes of a quality review system and the (governmental) decisions about the funding of higher education activities. Based on the experience of quality assessment in especially Western-Europe so far, we can argue that a direct, rigid relationship between quality review reports and funding decisions should not be established. By a direct, rigid relationship we mean that the quality judgements are the only input into the funding process, which, moreover, is a simple function of the quality judgement: 'good' education means $x$ extra money, and 'bad' education means $x$ money less. Such an 'automatic' direct relationship will probably harm the operation of a quality assessment system. All the more so as funding decisions presently tend to be cut backs (negative sanctions) rather than incentives (positive sanctions). The danger of this is that it may lead to a compliance culture, the only aim of which will be to appear to meet the criteria formulated, irrespective of whether those criteria are appropriate in the context of specific institutions or not. In such a rigid relationship academics and institutions will distrust the external review teams and they will produce self-evaluation studies in compliance with perceived criteria but with little real interest. Relating a system of rigid and direct rewards and sanctions to the delicate mechanisms of quality assessment may have a very negative effect on the operation of the system. In France, the Comité National d'Evaluation has understood these dangers. The evaluations performed by the Committee do not have a direct impact on state subventions to the institutions. The new procedures for quality assessment in the United Kingdom also do not imply a direct relationship between quality management and funding on a large scale. Moreover, the amounts of money involved in the funding councils' judgements seem to be fairly marginal for the moment, thereby mitigating any possible negative effect. Also, the quality audits of the new quality council for higher education, continuing the role of the AAU, have no direct link to funding either.

The above does not imply that an indirect, non-automatic relationship between quality management and funding decisions should also be rejected. On the contrary, as the experiences in the USA and Canada as well as the new approaches in France and the United Kingdom show, such an indirect relationship, where quality 
judgements are one - but not the only one - of the inputs into the policy processes leading to funding decision, could very well be part of the general model of quality assessment suggested here. An indirect relationship would imply that national governments will only provide the necessary financial means to higher education institutions if these institutions (and the various units within these institutions) can show that they have submitted themselves to at least one external judgement which is an accepted part of the general quality assessment system. Only if higher education institutions can show that they have offered their educational programmes for external review, should these institutions be eligible for governmental funding. Whether the funds provided by government are used to reward programmes that have been judged to be of good quality or to help programmes that received a negative qualification by an external review team, should be the decision of the higher education institution itself. It should be left to the discretion of the higher education institutions how they react to the outcomes of the quality assessment system. The decision to fund or not to fund an institution (or certain programmes within an institution) should, in this approach, only depend upon the willingness to submit the institutional activities to outside review.

\section{Perspective}

The elements presented here (touching upon the independent meta-level role of managing agent(s), upon self-evaluation, upon peer review and site visits, upon the degree of confidentiality of reporting, and upon the relationship between quality review outcomes and funding) together form the core of what could be called a general model of higher education quality assessment. A crucial question of course is whether such a general model offers a sound base for higher education institutions to keep their important place in society.

At the beginning of this article we argued that through history, higher education institutions have been rather successful in combining the two subcategories of the general concept of quality. On the one hand higher education institutions have always espoused the values of the search for truth and the pursuit of knowledge (the intrinsic qualities). On the other hand higher education institutions have responded with remarkable flexibility to the changing needs and pressures from their environment (the extrinsic qualities).

The recent call for quality assessment in higher education appears to be largely inspired by the wish of governments and other societal actors to underline the importance of the extrinsic qualities of higher education. The increasing participation rates in higher education and the growing costs have led to the wish to try to identify as clearly as possible the various quality aspects of the processes and products of higher education institutions.

Higher education institutions cannot be deaf to this increasing emphasis being put on their extrinsic qualities. As has been the case through the centuries, higher education institutions will have to respond to the call to show their value to society. 
They will have to accept (and in several countries they already have done so) the coming into existence of systems of quality assessment through which they can show their accountability to society.

However, it should not be forgotten that higher education institutions also have the task to emphasise their intrinsic qualities. In higher education the ideals of the search for truth and the pursuit of knowledge cannot just simply be discarded.

The general model of higher education quality assessment that appears to be developing in the various practices in several Western countries, will have to be judged on its capacity to combine both the intrinsic and the extrinsic dimensions of quality. Based on this perspective, we would like to argue that in any sensible system of higher education quality assessment both the traditional English model of a review by peers and the historical French model of providing accountability to external constituencies should be incorporated. Focusing on only one of these two models leads to a risky overestimation of specific functions and practices of higher education institutions. A quality assessment system that only consists of peer review without any reference to the needs outside the higher education system, implies the risk of an extreme isolation of the higher education institutions from the rest of society (and thus the denial of the legitimacy of their existence). A quality assessment system that is limited to only providing accountability to external constituencies denies some of the basic characteristics of higher education institutions and therefore implies the risk of not being taken seriously by the academic experts.

The remaining question is whether the core of the general model of quality assessment presented before is sufficiently able to combine the intrinsic and extrinsic dimensions of quality. Although it is too early to judge the empirical effects of the elements of the general model, it may be expected that this set of elements at least allows for the possibility to pay attention to the combination of both the intrinsic and the extrinsic dimensions of quality in higher education. The elements of the general model appear to deny the dominance of either of the two dimensions. As such, the core of the general model combines the two traditional approaches that are found in the history of higher education. By doing so the general model relates the present-day needs and experiences with the historical roots of higher education quality assessment.

\section{Note}

1. In Scotland, a judgement 'highly satisfactory' is also possible.

\section{References}

Barak, R.J. (1982). Program Review in Higher Education. Boulder, Colorado: National Center for Higher Education Management Systems.

Brennan, J. (1990). 'Quality assessment in the public sector in Great Britain', in Goedegebuure, L.C.J., Maassen, P.A.M., and Westerheijden, D.F. (eds.), Peer Review and Performance Indicators. Utrecht: Lemma. 
Cobban, A.B. (1975). The Medieval Universities, their development and organisation. London: Methuen $\& \mathrm{Co}$.

Cobban, A.B. (1988). The Medieval English Universities: Oxford and Cambridge to c. 1500. Berkeley: University of California Press.

Frederiks, M.M.H., Westerheijden, D.F., and Weusthof, P.J.M. (1993). Self-evaluation and Visiting Committees, paper EAIR-Forum, Turku, 14-18 August.

Guin, J. (1990). 'The reawakening of higher education in France', European Journal of Education 25, pp. 123-145.

Holdaway, E.A. (1988). 'Institutional self-study and the improvement of quality', in Kells, H.R., and van Vught, F.A. (eds.), Self-regulation, Self-study and Program Review in Higher Education. Utrecht: Lemma.

IHO (Inspectie Hoger Onderwijs) (1992). De Bestuurlijke Hantering van de Resultaten van de Externe Kwaliteitszorg in het Wetenschappelijk Ondersijs. De Meern, THO-report 1992-8.

Kells, H.R. (1989). 'University self-regulation in Europe, the need for an integrated system of program review', European Journal of Education 24, pp. 299-308.

Kells, H.R., and van Vught, F.A. (eds.) (1988). Self-regulation, Self-Study and Program Review in Higher Education. Utrecht: Lemma.

Neave, G. (1986). 'The all-seeing eye of the Prince in Western Europe', in Moodie, Gr.C. (ed.), Standards and Criteria in Higher Education. Guildford: NFER-Nelson.

Neave, G., and van Vught, F.A. (eds.) (1991). Prometheus Bound, the Changing Relationship Between Government and Higher Education in Western Europe. London: Pergamon.

Neave, M. (1991). Models of Quality Assessment in Europe. London, CNAA Discussion Paper 6.

Staropoli, A. (1991). 'The French Comité National d'Evaluation', in Craft, A. (ed.), Quality Assessment in Higher Education. London: Falmer.

VSNU (1990). Guide for External Program Review. Utrecht.

van Vught, F.A. (ed.) (1989). Governmental Strategies and Innovation in Higher Education. London: Jessica Kingsley.

van Vught, F.A., and Westerheijden, D.F. (1993). Quality Management and Quality Assurance in European Higher Education. Luxembourg: Office for official publications of the European Communities.

Vroeijenstijn, T.I., and Acherman, H. (1990). 'Control oriented versus improvement oriented quality assessment', in Goedegebuure, L.C.J., Maassen, P.A.M., and Westerheijden, D.F. (eds.), Peer Review and Performance Indicators. Utrecht: Lemma.

Williams, P.R. (1991). The CVCP Academic Audit Unit. Birmingham.

Young, D. (1990). 'The Academic Audit Unit, an organisation for university quality management', in Goedegebuure, L.C.J., Maassen, P.A.M., and Westerheijden, D.F. (eds.), Peer Review and Performance Indicators. Utrecht: Lemma. 